Pre-publication version. Published version to appear in A. Capone and F. Poggi (eds.):

Pragmatics and Law. New York. Springer, 2016: 121-139.

\title{
Legal Disagreements and Theories of Reference
}

\author{
Genoveva Martí (ICREA \& Universitat de Barcelona) \\ Lorena Ramírez-Ludeña (Pompeu Fabra University)
}

\begin{abstract}
According to Hartian positivists, law is a conventional practice that requires a convergence that includes not only the regularity of behavior but also of certain beliefs and attitudes. It is easy to conclude that in this framework the meaning of terms is determined by shared criteria that are transparent to all parties, a form of semantic descriptivism. This, at least, is the way in which Dworkin and his followers have interpreted Hart's positivist stance. The problem is that disagreements often arise on how to interpret the words of the law, and this fact seems to conflict with the emphasis of positivism on the idea of agreement, or so it is argued. If the meaning of legal terms depends on shared criteria, why do individuals disagree? And if they disagree, what does their disagreement consist in?

The discussion about how to account for interpretive disagreement can be seen as a discussion about how to account for the meaning of terms, and hence as a discussion about what kind of theory of meaning explains the existence of disagreement and the grounds for its resolution. In some cases a descriptivist approach to semantics seems to be correct, whereas other cases seem to speak in favor of non-descriptivist, theories of reference.

In this work we will examine critically how two competing approaches to meaning account for disagreements. We will argue that Hart's conventionalist stance does not commit him to descriptivism. That non-descriptivist theories of reference, properly understood, can account for a vast array of cases of interpretive disagreement and that and that an account of different kinds of disagreement can be provided from a conventionalist perspective within the framework of non-descriptivist theories of reference, and hence that the dispute between Dworkinians and Hartians does not depend on Hart's commitment to one or another semantic theory. We argue that both in and out of the legal context, a host of non-semantic considerations have to be considered relevant in the adjudication of disputes.
\end{abstract}

\section{1.- Introduction}

The problem of legal disagreements, initially raised by Ronald Dworkin against Hartian positivism, has been a focus of debate among theorists of law in recent years. ${ }^{1}$

\footnotetext{
${ }^{1}$ See (Hart 1994) and (Dworkin 1986). For an assessment of the debate see (Shapiro 2007).
} 
According to positivism, law is a conventional practice, a practice that requires a convergence that includes not only the regularity of behavior but also of certain beliefs and attitudes. ${ }^{2}$ It is easy to conclude that in this framework the meaning of terms is determined by shared criteria that are transparent to all parties, a form of semantic descriptivism. This is the way in which Dworkin and his followers have interpreted Hart's positivist stance.

The problem is that, frequently, disagreements arise on how to interpret the words of the law, and this fact contrasts with the emphasis of positivism on the idea of agreement, or so it is argued. If, according to positivism, the meaning of legal terms depends on shared criteria, why do individuals disagree? And if they disagree, what does their disagreement consist in? ${ }^{3}$

To a large extent, the discussion about how to account for interpretive disagreement can be seen as a discussion about how to account for the meaning of terms, and hence as a discussion about what kind of theory of meaning explains the existence of disagreement and the grounds for its resolution. In some cases a descriptivist approach to semantics seems to be favored, whereas other cases seem to speak in favor of non-descriptivist theories of reference. In this work we will examine critically how two competing approaches to meaning account for disagreements.

If Dworkin and his followers are right, Hart espouses a form of descriptivism. We will argue that Hart's conventionalist stance does not commit him to descriptivism. The discussion will also have consequences on the status of the more general debate between Hartians and Dworkinians as regards the role of conventions and moral considerations in the interpretation of the law.

\section{2.- Two approaches to reference}

The theory of reference has been dominated by two competing paradigms: descriptivism and the so-called new theory of reference (NTR).

Descriptivism, the view that the reference of an expression is determined by an associated definite description, used to be the universally accepted explanation of how reference occurs, of how words connect to the things they are used to talk about. From a descriptivist point of view, definite descriptions, i.e., expressions of the form the so and so constitute the paradigm of how pieces of language tie to the pieces of the world they are about.

The basic idea at the core of the traditional descriptivist stance is that speakers associate some attributive information to referential terms and, if that information singles out something uniquely, then when they use those words they refer to whatever satisfies or fits that information. Thus, for instance, a use of 'Ben Franklin' refers to Ben Franklin because a definite description that speakers associate with the name, for instance 'the inventor of bifocals', is uniquely satisfied by Ben Franklin. ${ }^{4}$

\footnotetext{
${ }^{2}$ We use the word "conventional" in a more flexible way than Lewis (1969) and the authors that discuss him. Regarding the conventional nature of law, see (Marmor 2009) and (Vilajosana 2010).

${ }^{3}$ There is an important difference, often missed, between interpretive disagreements, disagreements about the concept of law and disagreements about the sources of the law, among others. Here we will analyze only interpretive disagreements, that is, disagreements about the content of the law.

${ }^{4}$ Descriptivism finds its inspiration in the semantic theories of Gottlob Frege and Bertrand Russell. Russell (1910-1911 and other works) explicitly defended that referential terms such as proper names are abbreviations of definite descriptions. Frege's commitment to descriptivism is debatable. According to Frege (1892) what determines the reference of expressions is a sense, conceptual
} 
This is, needless to say, a very general and oversimplified characterization of descriptivism. Some versions of descriptivism would hold that different speakers attach possibly different descriptions to the same expression and each speaker refers to whatever satisfies the description she attaches. Other versions of descriptivism would take a more socialized stance and focus on the descriptions or clusters of descriptions that are connected with expressions at the level of a speakers' community. ${ }^{5}$ But no matter what the version, descriptivism is committed to two fundamental tenets: (1) that the referential link is mediated by descriptive information, that reference is not a simple semantic relation between, say, a name and its bearer: if a use of 'Ben Franklin' refers to a certain person, it is by virtue of the fact that the description associated with the name fits this person, and if nothing satisfies the description in question, then speakers are not referring to, or talking about, anything at all; (2) that the uniquely identifying information semantically associated with an expression is what a competent speaker grasps. It is precisely being in possession of that information, having internalized it, that makes a speaker competent with the use of a term. The description or the sense that determines reference is transparent to speakers.

The second approach to reference, often called simply new theory of reference, enters the scene in the 70s (thus, 'new theory' is more a name than a description) with Saul Kripke's 1970 lectures on Naming and Necessity (1980) and Keith Donnellan's 1970 article. Kripke and Donnellan criticized descriptivism rejecting the need of a descriptive backup for reference to occur. They argued that speakers do refer even when the descriptive information they associate with a name is insufficient to determine a unique object, and that they refer to "the right" referent even when the information they associate with the individual's name is erroneous. Thus speakers that use 'Feynman' refer to Feynman even if the information they associate with the name ('famous physicist') fits many people, and they refer to Columbus even if the description typically associated with the name ('the first European to set foot in America') actually fits someone Viking from the 11 th century. ${ }^{6}$

Of course speakers may, and often do, associate descriptions, concepts, connotations and whatnot with the words they use. The important point is that all that associated material does not explain how and what they refer to. But this is fundamentally a purely negative thesis. Descriptivism has an explanation of how a given use of, say, 'Ben Franklin' manages to designate an individual. If, as NTR postulates, the transparent background of definite descriptions is neither necessary nor sufficient to refer, how does reference occur?

According to NTR reference can be established by an act of ostension in which a name is bestowed by a declaration such as 'let us call this individual 'Ben'. Subsequently, users of 'Ben' refer to the bearer of the name by virtue of being part of a network of users, a chain of communication in which each link has received 'Ben' from a previous link, and uses it with the intention to refer to the bearer at the origin of the chain.

Of course, a name can be bestowed, and so reference can be established, via a description (as, for instance, when we decide to call 'Arcturus' the brightest star in the northern celestial

material grasped by speakers that constitutes a mode of presentation of the reference. Nevertheless, traditionally a substantial amount of Fregean followers have cashed out Frege's stance as a form of descriptivism.

${ }^{5}$ John Searle (1958) was the prime proponent of the so called 'cluster theory' according to which the referent of a use of a name is the individual that satisfies a sufficient number of the descriptive information socially connected with the name.

${ }^{6}$ After Devitt and Sterelny (1999) the argument that speakers refer in the absence of uniquely identifying information is also known as the ignorance argument, and the argument that they refer but not to the individual that satisfies the description they associate is known as the error argument. 
hemisphere), but the role of the description, according to NTR, is just that of establishing reference; the description is inoperative in subsequent uses of 'Arcturus', as inoperative as the original ostension in the case of 'Ben'. We do not ostend Ben when we use the name 'Ben'7 and our use of 'Arcturus' does not refer in virtue of a description we have internalized. ${ }^{8}$

Whereas for the descriptivist speakers refer in virtue of being in possession of a description that determines the reference of each of their uses, for the new theorist speakers refer in virtue of their objective position in the network or chain of communication. What determines the reference of each use may well not be transparent to the speaker, according to NTR.

The chain of communication picture, introduced by Kripke and Donnellan, constitutes a positive explanation of how a use of an expression connects to other uses and reaches back to the referent. Nevertheless, it is important to notice that the picture in and of itself is not incompatible with descriptivism. The chain of communication is a mechanism of transmission of meaning from generation to generation, not a semantic theory of how the reference of a particular use of a name is determined. ${ }^{9}$ According to the descriptivist, names are bestowed by associating them with descriptions, and so a descriptivist could argue that speakers in the chain of communication acquire from other speakers the description that determines the reference. The transmission of a description would be that which, according to descriptivists, makes speakers join as new links in a given chain, and what makes it possible for them to use a name competently to refer to its bearer. It is ignorance and error arguments that show that it is not a description that determines the referent, even if speakers de facto associate one and pass it from link to link. For those arguments show that speakers can refer to the individual at the end of the chain in the absence of uniquely identifying information, and in the presence of information that fits someone else or nothing at all. Against the descriptivist, the new theorist defends that all that is required for reference to occur is the ostension or the description that establishes reference in the original act of naming, and the transmission of the name to new links that intend their use to match previous usage. ${ }^{10}$

So far we have concentrated on the simpler case of proper names, the paradigmatic referential expressions. But both descriptivism and NTR are general theories about how expressions connect to the world. They encompass both singular and general terms, and hence they apply also to terms such as 'tomato', 'water', 'whale' or 'dead'.

The descriptivist position is the same as regards singular and general terms. In the case of words such as 'whale', 'tomato', etc., speakers associate a description that determines the domain of application of the term.

\footnotetext{
${ }^{7}$ Except perhaps figuratively, as when Ruth Barcan Marcus famously characterized names as 'the long finger of ostension'. See (Marcus 1993).

${ }^{8}$ In fact, we may discover that the individual we have been calling 'Ben' was not the individual the name introducer did in fact ostend originally. And we may discover that the description used to introduce 'Arcturus' applies to something else. As long as a practice has been established, those discoveries need not force any change in usage.

${ }^{9}$ See (Almog 1984) for discussion.

${ }^{10}$ The chain of communication picture is often presented as the causal theory of reference. The term is misleading in more than one way. First, because it is not a theory of reference. The chain of communication leads back from use to use to the introduction of a name, the act in which reference is established. The chain does not itself establish reference. Reference has to be there for the transmission in the chain to occur. Second, because the role of causation in the picture is far from clear. In fact, Kripke and Donnellan stress the social character of the picture, but they often do not even use the word 'causal' in describing it. It was Michael Devitt (1981) who incorporated the picture into a causal theory of reference establishment and transmission.
} 
According to NTR, a general term, like a singular term, can also be introduced by a description whose role is just to establish the domain of application. But typically the connection is established by ostension. Of course the introducer of a general term does not ostend, say, all the tigers and all the samples of water. In (1975) Putnam imagines a term such as 'water' being introduced by pointing at some samples of a substance in a lake or a river. Those original samples count as paradigmatic instances, and then other samples, or other individuals in the case of count nouns, are classified by their similarity to the paradigm cases. In a case such as water, Putnam and Kripke contend, speakers begin to use the term 'water' with the intention of applying it to samples of the same substance.

What makes a sample of a liquid be water (and determines the correct application of 'water') may not be epistemically accessible to users. In fact, having the molecular structure $\mathrm{H}_{2} \mathrm{O}$ is what determines whether a sample of a liquid is or is not water and thus determines the domain of application of the word 'water'. But the discovery of the nature or essence of water occurred long after the word 'water' had been in use: knowledge of the reference determining factor in this case did not antecede the establishment of the usage of 'water'. ${ }^{11}$

A descriptivist cannot accept that the correct application of a term is ultimately grounded on something unknown to the linguistic community, something competent speakers have no cognitive access to, such as a hidden essence or underlying nature. The Kripke-Putnam approach opens the door to a completely external criterion of determination of reference or domain of application.

It is often taken for granted (see for instance Bix 1993: 162 and ff. and Marmor 2005: 65 and ff.) that the Kripke-Putnam approach to the semantics of general terms is committed to essentialism, the postulation of shared underlying natures that are not immediately accessible or observable and can be discovered only by scientific investigation. But the commitment to essentialism is not constitutive of the approach. On the Kripke-Putnam model some samples or individuals are treated as paradigms, and other instances are classified as members of the same kind by virtue of their similarity to the paradigms. The similarity could well be superficial (based on how new yet to be classified objects or samples appear or look), or based on sameness of function. The Kripke-Putnam model does not impose that the relevant criterion is essence. ${ }^{12}$ The novelty of the view is rather that it opens the door to the possibility that the similarity that is responsible for certain classification into kinds be entirely external to the minds of speakers.

It does happen, though, that in classifying the natural world we tend to trust more an essentialist picture, and to expect our classifications, and our usage of kind terms, to be tied to the natures of things, for we trust science to discover the ultimate features of reality that are responsible for superficial behavior, appearance and causal interactions. It is reasonable to trust that scientific classifications get to the real joints of the world and that they help us to predict and explain better than classifications based on purely superficial features.

There is also a semantic reason that explains the pervasive view that the Kripke-Putnam model is committed to essentialism and it is the allegiance to the claim, shared by descriptivists and new theorists alike, that the domain of application of a term is fixed once and for all when the term is incorporated into the language. If water or tigers have an

\footnotetext{
${ }^{11}$ Just to forestall some confusions, obviously we could have used the word 'water' to refer to some other substance. But in our discussion about meaning, the focus is on what our words do mean, and on how they are in fact used, not on what they could have meant, or referred to.

${ }^{12}$ And which criteria of similarity are ultimately relevant in classification depends on all kinds of nonsemantic factors.
} 
underlying essence that determines membership in the kind, it is fixed whether or not a yet to be classified individual or sample is water or a tiger, and hence whether it falls under the extension of the corresponding terms. It is, or appears to be, a perfectly plausible assumption to make. ${ }^{13}$ But it is not an intrinsic commitment of the Kripke-Putnam model, and Putnam himself points that out when he describes how samples of liquid are classified as being the same liquid as the original paradigms of water in terms of their important physical properties:

$x$ bears the relation same L $_{\text {to }} y$ just in case (1) $x$ and $y$ are both liquids, and (2) $x$ and $y$ agree in important physical properties ... Importance is an interest relative notion. Normally the "important" properties of a liquid or solid, etc., are the ones that are structurally important: the ones that specify what the liquid or solid, etc., is ultimately made out of elementary particles, or hydrogen and oxygen, or earth, air, fire, water, or whatever- and how they are arranged or combined to produce superficial characteristics. From this point of view the important characteristic of a typical bit of water is consisting of $\mathrm{H}_{2} \mathrm{O}$. But it may or may not be important that there are impurities; thus, in one context "water" may mean chemically pure water, while in another it may mean the stuff in Lake Michigan. And structure may sometimes be unimportant; thus one may sometimes refer to XYZ [some other substance] as water if one is using it as water. Again, normally it is important that water is in the liquid state; but sometimes it is unimportant, and one may refer to a single $\mathrm{H}_{2} \mathrm{O}$ molecule as water, or to the water vapor as water ("water in the air"). (Putnam 1975: 239)

The appeal to essences and the expectation that expert scientists will reveal to us the natures of things and substances is perfectly understandable because we want to know how the world functions. But the rejection of the assumption of fixity of the domain is not incompatible with the Kripke-Putnam model of the meaning of kind terms.

\section{3.- Disagreements and legal disagreements}

Descriptivism and NTR are different theories of reference and they offer different treatments of the nature of disagreements.

According to NTR different speakers may associate different concepts or different descriptive information with an expression, and yet they may be talking about the same things, for the descriptions they attach do not determine what they refer to. It is possible for two speakers to talk about the same thing or phenomenon and to agree or disagree about its properties or its very nature, even if each of them would describe what she is talking about in radically different ways. For, according to NTR, speakers do refer to the things or phenomena that are at the origin of the referential practice they engage in, even if the concepts or descriptions they associate apply to something different or even to nothing at all.

This explains how, for instance, scientists can disagree about the nature of substances or phenomena when their conceptions differ; how it makes sense to dispute as regards who is right and who is wrong even when the fundamental conceptions entertained by different

\footnotetext{
${ }^{13}$ In section 5 we explore some of the consequences of dropping the assumption that the domain is fixed once and for all.
} 
scientists apply to different things (or when one of them or both do not apply to anything), for it is possible to talk about something to which the conceptions entertained do not apply.

Descriptivism, on the other hand, seems to have more of a problem explaining those kinds of disagreements. From this perspective, speakers refer to whatever satisfies the descriptive material they associate with words, and if nothing satisfies the material, then the associated word has no reference, no domain of application. Two speakers that associate with the same word descriptions that do not coincide in what they determine, are not referring to the same things. As a consequence, they cannot disagree about the character and properties of one and the same thing, if their respective conceptions do not coincide.

The impact on the explanation of scientific disagreement is obvious. It would seem that scientists that have different fundamental conceptions are really talking about different things, and hence they are not communicating, they are talking past each other and hence not really disagreeing. This is a consequence that some Kuhnians may welcome and embrace. But it leaves a lot of real life, day to day scientific practice unexplained.

All these issues arise in a legal context also. Dworkin (1986: 4-5) has distinguished between empirical and theoretical disagreements and he has argued that descriptivists can account for empirical disagreement, the kind where people disagree whether a particular thing has or not a particular property, but they have difficulty in accounting for theoretical disagreement, the kind that occurs when the concepts or descriptions they entertain are different. ${ }^{14}$ For instance, from the descriptivist perspective two people that include 'ceasing to breath' in their shared description or concept of death can have an empirical disagreement that will turn on whether someone is or is not breathing. However a descriptivist would seem to have trouble explaining that there can be disagreement when two people do not share the concept of death, for instance when one of them considers that a flat EEG constitutes death and the other one does not, so when one of them asserts 'this person is dead' and the other one replies 'this person is not dead' they may well both be expressing a truth, and there seems to be no way, within the framework, not only to conclude that one is right and the other one wrong, but even no way to conclude that there is a disagreement. It would seem that the disagreement can only be interpreted as a dispute about which concept or which description should be associated with 'is dead'. Dworkin has interpreted Hart's conventionalist stance as committed to a descriptivist semantics, and he has criticized Hart for not being able to account for theoretical disagreements satisfactorily, for the disagreement about which concept or description should be associated with which term, turns an important issue into a purely terminological nonsubstantial dispute. ${ }^{15}$

In a case such as death, in which something rather crucial is at stake, NTR provides a more satisfactory account. First of all, it explains the existence of a disagreement in spite of the presence of radically different concepts of death and therefore it sustains an adjudication of

\footnotetext{
${ }^{14}$ Dworkin (2006: 9) talks about criterial concepts, but his reconstruction of them is very close to what we have presented as descriptivism.

${ }^{15}$ In a recent series of papers David Plunkett and Timothy Sundell (2013a, 2013b and 2014) have assumed the Dworkinian reading of Hart's approach, characterizing Hart as a descriptivist (a characterization that, as we will explain below, we do not share). For Plunkett and Sundell the disagreement does exist and it is indeed a disagreement about which meaning or which concept should be associated with a given term, so the disagreement, they claim, occurs at a metalinguistic and pragmatic level. However, they reject the claim that the disagreement is not substantive, for it can have substantive ethical, social or economic motivations and substantive consequences. Our position is somewhat germane to Plunkett's and Sundell's although we have some divergences. More on this in section 4 .
} 
right and wrong. Two speakers may have radically different concepts of death, but as members of a linguistic community, they are links in a chain of communication that has its origin in one and the same phenomenon, and hence they are talking and disputing about the same thing. The disagreement is a genuine disagreement about the nature of death, i.e., about the nature of one and the same phenomenon, and experts, those that seek to acquire genuine knowledge about the nature of phenomena, have a decisive role when it comes to performing such an adjudication. As Michael Moore has pointed out:

Both we and they [our ancestors] intended to refer to the thing, the naturally occurring kind of event, that death is. If they knew what we know about revivability of persons submerged in cold water, they would also say that such persons are not dead. They would say this because they, like we, intended to refer to a thing whose nature is partially known; and they, like we, would change the conventional indicators of when someone is dead whenever a better scientific theory comes along that demands that we do so. (Moore, 1985: 297298)

NTR is in a much better position to explain cases like this, in which the community's interests have always been to talk about something on the basis of its nature, which may be unknown or only partially known. NTR explains why a group of speakers that had a concept of death according to which stopping to breath for a few minutes was sufficient to be declared dead would be wrong. It explains also why we can say that in the past, or in other cultures, people might have made mistakes in considering someone dead. That they were or are wrong, naturally does not mean they should be considered legally responsible. A few years after the atomic weight of gold was discovered, it made sense to say that some people had mistakenly taken a ring to be made of gold, but this does not entail that those that had confused fools gold with real gold should be legally responsible. They simply didn't know, and they could not have known. As Moore has pointed out:
Imagine the doctor who relied upon the conventional indicators of death and who cut the heart out of a (conventionally) "dead" person who was really quite alive [...]. The doctor cut out the heart, one might say, relying on the conventional indicators of when some body is a corpse and when it is a person. Such a doctor does have a valid claim of surprise, but that does not weigh against application of the realist theory of meaning to both "death" and "human being." Applying such a theory will prohibit the acts the doctor did, yet will allow the doctor to avoid prosecution for murder because of the lack of requisite mental state. (Moore 1985:324-5)

If the characterization of Hart's positivism as committed to descriptivism is correct, positivism would have a problem in accounting for the kinds of disagreements that occur when the criterion of similarity is not transparent or is, as Moore puts it, partially known. Hart has been interpreted as committed to the view that the meaning of specific terms relies on shared concepts. This would seem to close the door to the interpretation of terms such as 'death' or 'gold' in the way suggested by NTR for parties cannot have epistemic access, and thus share a criterion of classification, or of application of a term, that is not transparent to them.

But it seems to us that Hart is not committed to any form of semantic descriptivism. The agreement that Hart postulates can also be the agreement that the application of a term is determined by the essence or the nature of a thing or phenomenon. His emphasis on 
conventionalism, we believe, points simply towards the view that conventional usage is relevant. The convergence that the interpretation of the law requires, according to Hart, need not be an agreement on the contents of our conceptions; the agreement that has to be reached is an agreement about the relevant usage. ${ }^{16}$

\section{4.- Disagreements and the New Theory of Reference}

In every day life, and in legal contexts, there is an important kind of disagreement that does not fit the model just discussed, a disagreement that occurs even when there is no dispute about the nature of things and there is no empirical disagreement either. In Nix v. Helden, resolved by the US Supreme Court in 1893 (149 US 304, 1893), there was a dispute about whether tomatoes are included in a regulation that makes reference to fruits. The case concerned the action of tomato merchants seeking to recover back duties from a dutycollector (Hedden) on the grounds that tomatoes are not vegetables but duty-free fruit. The Supreme Court found in favor of Hedden. In this case, everybody agreed that the scientific classification of tomatoes as fruits is correct, and there is no empirical disagreement either about whether certain items belong to the botanical kind in question. Nevertheless, there is a consolidated use of the word 'tomato' in the community that classifies tomatoes under the umbrella of vegetables. According to Philips, "the court's determination thus reflects its view that the relevant tariff act intended 'vegetable' in its common language or culinary sense. The issue is not whether tomatoes are fruit or vegetables" (Philips, 2014: 381) ${ }^{17}$.

It has often been pointed out that cases like this one constitute a problem for NTR (see for example Patterson 1989a and 1989b). The reason is that, if the Kripke-Putnam model were correct, the nature of tomatoes, which has been discovered by expert botanists, would be determinant in the dispute, in the same way that the nature of water is determinant in a dispute as to whether some liquid is or is not water. Hence there should be no disagreement, and therefore there should no dispute: tomatoes are fruits, end of discussion.

The descriptivist, on the other hand, seems to be in a better position because she does not have to commit to the scientific usage as the correct one. The descriptivist can accept that laypeople associate a description or a sense to a word that selects a domain of application that does not coincide with the experts' without thereby being wrong. So, the laypeople that count a serving of tomatoes as a serving of vegetables, and the judge that sides with the laypeople and decides to exclude tomatoes from the regulations that apply to fruits are not making any mistake and they need no correction on the part of the experts. Their usage of the word 'tomato' is correct, for the descriptive information they associate to the word determines that tomatoes are vegetables.

Nevertheless, if we understand that in the Nix v. Helden case there are different descriptions at work, according to the descriptivists the parts cannot be arguing about the same thing, and thus the disagreement has to interpreted as a dispute about which sense should be considered relevant in the context in question, a purely terminological disagreement according to Dworkin.

\footnotetext{
${ }^{16}$ See (Ramírez-Ludeña 2015) for discussion.

${ }^{17}$ See also (Moreso 2010).
} 
We will argue that, in spite of the generalized perception, the presence of different usages in a community does not present a problem for NTR when it comes to accounting for the nature of disagreements, such as the one at stake in Nix v. Helden. In fact, the NTR treatment of this kind of disagreements is not fundamentally different from the descriptivist response.

A natural description of the situation in the case is the following: what the judge is doing in Nix v. Helden is deciding between two established uses of 'fruit' (and of 'vegetables'), two chains of communication that are already present in the community. Both chains have their origin in paradigmatic instances of fruit, and in both cases items are classified according to their similarity to those paradigmatic instances. In one case, the relevant similarity depends on the nature of the exemplars, a nature studied by botanical science. In the other case, the similarity stressed, as Phillips has pointed out, is that tomatoes:

whether eaten cooked or raw, are, like potatoes, carrots, parsnips, turnips, beets, cauliflower, cabbage, celery and lettuce, usually served at dinner in, with or after the soup, fish or meats which constitute the principal part of the repast, and not, like fruits generally, as dessert. (Phillips 2014: 381)

It is important to stress that both chains of use are present in the community. Most people, scientists and laypeople alike, know that tomatoes are fruits, but even a botanist, when asked 'Do you like fruit in your salad?' will very likely not respond 'Of course!' just because she usually adds tomato to her salads. She will understand quite readily that the question is about berries, apples or oranges. ${ }^{18}$

The choice of a usage over another one depends on all kinds of non-semantic factors, having to do with the broad context of use. As Putnam observed: "in one context 'water' may mean chemically pure water, while in another it may mean the stuff in Lake Michigan" (Putnam 1975: 239). So interpreted the situation is not different from cases of ambiguity: what favors an interpretation of 'bank' as a financial institution rather than the bank of a river when a speaker utters 'let us meet at the bank' has to do with the background situation, history of the conversation and the setting in which the utterance occurs.

It may seem that if the issue turns on deciding which established use is going to be considered operative there is no error, no right or wrong to adjudicate. But we think that there is right or wrong, in more than one sense.

First, it is clear that in a scientific dispute it is wrong to say that tomatoes are vegetables. And in the context of grocery stores and people's kitchens, where it matters, for instance, what is shipped, displayed and sold with what, and what is typical to put in a soup or in a main dish, it is not wrong to say that tomatoes are vegetables, but it would be wrong to say that oranges, for instance, are, because there is no established practice, in that setting, of applying 'vegetable' to oranges.

\footnotetext{
${ }^{18}$ Someone may argue that the phenomenon described here is purely pragmatic, that the botanist interprets the intention of the speaker not to include tomatoes among fruits. It seems to us that the phenomenon is too pervasive, consolidated and conventionalized to be dismissed as a pure case of speaker reference.
} 
Second, the choice of one or another usage as relevant for interpretation may also be mistaken. The setting, the history of the conversation (in everyday life), or the type of dispute (in the legal scene), may determine that one context of usage, and hence a chain or practice is the relevant one. For instance, suppose that a speaker has been participating in a conversation about money and financial institutions, a conversation that has ended with a group of participants uttering 'we are going to the bank to get some cash'. If the speaker says 'I will meet you at the bank' and proceeds to walk to the bank of a nearby river that was never mentioned in the conversation, it is not particularly salient or a usual place for the group to meet, the speaker is arguably speaking falsely. The intentions of an individual speaker are not always sufficient to determine the proposition that she expressed, and hence, the commitments that she engages in. The issue here is not semantic; it is an issue that has to do with the appropriate conditions of choice of a usage over another (so, it can be characterized as pre-semantic or meta-semantic). And it is not a pragmatic issue either; for the speaker is not taking a conventionally established use and twisting it in a non-conventional way. So, the situation should not be described in terms of a clash of speaker meaning and semantic meaning.

In the legal scene it would be a mistake to interpret a contract that specifies that a unit has to be left empty when vacated by the tenants in terms of the scientific use of 'empty' as when a physicist talks about empty space. So, there is no discussion in such a case as to what chain of communication is relevant.

Other legal cases are less clear. For instance, in Nix v. Helden it is not obvious that the judge would have made a mistake if she had declared that the relevant use was the scientific use and therefore that tomatoes were to be treated as fruits, for the non-semantic considerations (commercial, culinary, economical, scientific...) that should determine which usage is relevant are not always distinct as many subjects with different interests and different backgrounds can be involved in the same dispute. ${ }^{19}$

Often, because our trust in science, the scientific use trickles down and becomes pervasive. Everybody would be scandalized nowadays if whales were classified commercially as fish. But as Mark Sainsbury (2014) has reminded us, in a legal dispute in 1818, whale oil was classified as fish oil. At the time, there were two rather established uses of 'whale', the scientific one that classified them as mammals, and a commercial one that classified them together with other 'creatures of the sea'. Nowadays one of those uses is defunct, one chain of communication has ceased to exist, and the practice that did not distinguish whales from all other creatures of the sea is dead or seen as extremely deviant. ${ }^{20}$ Because the scientific use has become socially prevalent we look back and say that those that classified whales as fish were wrong (and in a scientific context, since the scientific use is, or should be, always prevalent the adjudication of right and wrong leaves no room to doubt). In the case of death, as Moore has pointed out, we always intended to refer to the naturally occurring phenomenon.

In the future, it may also happen that the scientific practice as regards tomatoes becomes prevalent and that a few years down the road no one thinks of tomatoes as vegetables. This may depend also on other factors like, perhaps, some famous chef insisting that tomatoes are

\footnotetext{
${ }^{19}$ In section 5 we explore other cases where there is, arguably, some indeterminacy as regards which usages and which contexts of use are relevant and even whether there is a sanctioned usage at all.

${ }^{20}$ See (Jackman 1999) for a defense of the claim that ascriptions of content, and hence the truth value of claims, may depend on future developments of usage. More on this in section 5
} 
a neglected fruit, giving rise to a new trend of cooking pies, sweets and other desserts made with tomatoes. We feel safe in predicting that this will not be the fate of 'empty', simply because the conditions under which scientists use 'empty' are not reproducible in everyday life. Nobody would expect that an empty apartment should be devoid of matter.

The extent to which we admit of different uses or focus on one single use, one set of known or partially known similarities, depends on many considerations. Those considerations may be ethical, social or economical and driven by all kinds of interests. But they are not considerations about the semantics of the terms.

The explanation given here is offered entirely within the framework of NTR, and it is an explanation that, in our view, accounts naturally for the cases of disagreement discussed so far. The theory of reference underlying our discussion is committed to the Kripke-Putnam model, but as we have argued above, the Kripke-Putnam model is not committed to the claim that the only meaning of a kind term is the meaning determined by the nature or the essence of the kind, and our account results from simply freeing the Kripke-Putnam model from the allegiance to the claim that the domain of application of a kind term has to be determined by the essence of the kind.

The assumption that essentialism is a constitutive element of the Kripke-Putnam model is so pervasive, that often arguments against essentialism are presented as criticisms of the model. ${ }^{21}$ It is important to stress that we are not arguing against essentialism here; the argument is against the presumption that the Kripke-Putnam model requires the domain of application of a kind term to be determined by an underlying nature or essence. The presumption that the Kripke-Putnam model is committed to the view that the relevant similarities responsible for classifying things or samples as members of a kind have to be underlying essences is responsible also for the pervasive assumption that the model does not provide an adequate semantic account of terms for nominal kinds or artificial kinds. But all the model postulates is that the classification of things or samples into kinds depends on the similarities to original paradigms. The similarity can be observable, capturable even by a definite description. The Kripke-Putnam model can incorporate and account for descriptive uses. It simply accounts for more.

Our position is germane in many respects to that of Plunkett and Sundell, in particular we agree that the relevant disagreement is not about the content or the subject matter (namely, in Nix v. Helden it is not about the nature and properties of tomatoes). It is a disagreement that turns on different uses or meanings of a term. ${ }^{22}$ But we have arrived at this position starting from the perspective of NTR without assuming descriptivism. ${ }^{23}$

In all these cases, again, it seems to us that the explanation here provided is compatible with Hart's position. As we indicated in section 3, we believe that the best way to understand Hart's

\footnotetext{
${ }^{21}$ See (Dupré 1981).

${ }^{22}$ Plunkett and Sundell (2013a) ellaborate on the importance of what they characterize as "pragmatic" considerations. We prefer to reserve the word "pragmatics" to cases where an expression with an established meaning is used non-conventionally. In the cases discussed here the dispute turns on a choice between established meanings, and there is no issue here about non-conventionality. The considerations are, certainly, non-semantic and they involve social factors, interests, facts about the context of use, the history of conversations and exchanges, etc.

${ }^{23}$ It should be noted also that Plunkett and Sundell, hypothesize that their position is compatible with non-descriptivism (Plunkett and Sundell, 2013b: 26 and ff.).
} 
conventionalism is as emphasizing the crucial role of conventional usage. The agreement that matters is not at the level of the specific content of terms; it is rather an agreement about the relevant use, and that is what the dispute turns on. In the cases discussed in this section, there are multiple uses of a given term in a given community, and in general there is an agreement as regards which use or chain of communication is relevant. So Hart can assume that in this legal domain the law provides an answer that is determined by convention.

It usually taken for granted that these cases pose a problem for NTR, and we have shown that this perception is not correct, if we acknowledge that NTR is not committed to the claim that a term's application can be determined only by underlying nature. The explanation that a descriptivist would give of these cases also goes along the same lines. This is not surprising since, as we noted previously, the postulation of chains of communication is not incompatible with descriptivism. Certainly, an individualistic descriptivist, one that espoused the view that there are no constraints to the descriptions or senses different people attach to words would indeed have a problem explaining these kinds of disagreements and their resolution, but this kind of descriptivist has all kinds of problems, including explaining successful communication and the attribution of beliefs to others. It is true that NTR cannot have these kinds of problems, for individualism is excluded from the theory of reference in NTR. But the descriptivist that accepts the presence of conventionally determined senses or concepts as the meanings of words, a descriptivist that accepts the presence of socially sanctioned uses that correspond to social chains of communication, can account for the cases discussed in this section, and similar ones, on the same basis as the proponent of NTR. The cases that do constitute a problem for descriptivism are those in which the criterion of similarity is not totally transparent to speakers, like the cases of 'death' or 'gold'.

The existence of different uses of an expression in a community poses no problem when it comes to offering an account of the kinds of interpretive disagreements considered in this section. The disagreement requires a choice of usage and a determination of the relevant context of use, and the resolution of the disagreement is based on considerations that are external to semantics.

\section{5.- Indeterminacy}

As we pointed out before, there are circumstances, both in everyday life and in legal contexts, when it is not clear what the relevant use of an expression is. The 'bank' example discussed in section 4 points towards a relatively clear decision in case of dispute. But if, for instance, two speakers find the instruction 'go to the bank' in a game of clues, it may be impossible to find elements that would adjudicate a dispute arising from the fact that one of them went to the bank of the river and the other one to the local branch of Bank of America. A dispute in this case, is simply not resolvable, and in an important sense, it would be a mistake to try to resolve it; for it should not arise. A descriptivist and a proponent of NTR alike will appreciate the difficulty here and for the same reasons. One might expect that in the legal scene cases like the one just described are atypical, for the legal dispute usually involves parties with a history of use and hence it does not revolve around 'out of the blue' uses of expressions. Nevertheless, there are cases, such as Nix v. Helden that show that there are often elements pointing reasonably in different directions and a certain level of indeterminacy as regards the appropriate choice.

Other cases where indeterminacy creeps in are those in which the domain of application of a term is extended in an unexpected way. Plunkett and Sundell (2014) mention a debate, discussed by Peter Ludlow (2008), as to whether Secretariat could be in the ESPN list of the 
greatest athletes of the 20th century. ${ }^{24}$ Up to 1999, as far as we can tell, the word 'athlete' had been applied only to humans, and a lively debate erupted as to whether a horse could be said to be an athlete. The debate was about whether the meaning of the term licensed its application to non-humans. From the point of view of a descriptivist theory, the question turns on whether the description associated with 'athlete' contains reference to human beings; and from the point of view of NTR it turns on whether the relevant similarity on which the classification depends includes the property of being human. Both positions, sticking to the claim that the domain of application of a term should be determined once and for all, can discuss whether applying 'athlete' to Secretariat constitutes a change of meaning.

It is however questionable, whether the application of 'athlete' to non-humans should be seen as a change of meaning and perhaps there is another explanation, one that can be provided if we free ourselves from the presumption that the domain of application is fixed once and for all. ${ }^{25}$ For as John Stuart Mill argued:

... objects bear a general resemblance to one another, which leads to their being familiarly classed together under a common name, while ... it is not immediately apparent what are the particular attributes upon the possession of which in common by them all, their general resemblance depends (Mill 1843, Book I chapter $2 \S 5$ ).

And as "new objects are continually presenting themselves to men, women and children, which they are called upon to class" (Mill 1843), a different set of similarities that guide the application of the term may be highlighted or disregarded giving rise to extensions of the domain of application in one direction or another. It is not clear that this always constitutes a change in meaning, as long as a level of consistency with past and present practice is preserved. Along these lines, Henry Jackman expresses the point as follows:

There may be a number of possible equilibria for an individual's or society's practice of using a term. We can call an equilibrium 'accessible' if it both preserves a sufficient number of entrenched beliefs and applications, and has no competitor that preserves significantly more ... A term's usage at a time may have a number of equilibria accessible to it. These accessible equilibria set limits upon how much linguistic usage can change within a practice, without changing the meaning of the terms involved. A practice can evolve as its characterization of a term's meaning is made more determinate, but it need not actually be viewed as changing unless it settles on an equilibrium that was not a member of the set originally accessible to it. As long as the practice remains the same, so does the meaning of the term tied to it. (Jackman 1999: $160-1)$

In the case of 'athlete' the proposal to extend the domain of application does not seem to have enjoyed much success. But other cases in the past have been successful. The people that first thought of using 'keep feeding the printer one page at a time' or that uttered 'the ATM swallowed my card!' were extending terms whose domain of application at the time had not included non-living organisms. Because the people were popular, authoritative, or because

\footnotetext{
${ }^{24}$ Secretariat was number 35, appearing under the category of horse racing, beating Bill Shoemaker (number 57) and Eddie Arcaro (number 66) both Hall of Fame jockeys and also under the category of horse racing. There were two other non-humans in the ESPN list, both racing horses: Man o'War (number 84) and Citation (number 97)

${ }^{25}$ We discuss now some of the consequences of dropping that assumption, as promised in section 2 and footnote 10 .
} 
other people thought that their non-standard use was clever, the linguistic practice followed that path.

Whether we wish to interpret those cases as an extension of the domain without a change in meaning, or as a change (gradual or punctual) in meaning, the fact is that the success in establishing a practice of using 'athlete', 'feed', 'swallow' etc. in a certain way depends on all kinds of factors that are out of the semantic sphere. The explorers that called an island 'Madagascar' thinking that they were following the natives' practice, were making a mistake, but because of their authority, political power, and the fact that they were the ones drawing and distributing maps, our uses of 'Madagascar' refer to the island, and not to a piece of Africa's mainland. ${ }^{26}$ Who manages to establish a linguistic practice is a matter of success, and that success sometimes depends on having some authority. In legal disputes that involve cases in which there is this kind of indeterminacy as to what the domain of application of a term includes, the judge may have been invested by society with that authority. ${ }^{27}$ But the authority, even in the case of the judge, has limits. Society would not accept, and rightly so, a legal classification of tomatoes as artifacts. ${ }^{28} 29$

Recent legal disputes over same-sex marriage have turned often on the alleged meaning of 'marriage' as a union between man and woman, and the US Supreme Court decision in the Obergefell v. Hodges case (576 U.S.__ 2015) has been interpreted by some, even by some of the judges discussing the case, as endorsing a change of meaning. But looking at Anthony Kennedy's statement of the majority opinion from the perspective suggested by John Stuart Mill's words, and endorsed by Jackman, it would rather seem that the extension of the domain of application is already present in the community and it is underwritten by the stress on properties that the ideal of marriage embodies: "love, fidelity, devotion, sacrifice, and family" (576 U.S. 2015: 28).

Legal disputes in which there are no sufficient elements to determine a relevant use, or cases that involve an extension of the domain of application of a term, are cases of legal indeterminacy, the kinds of cases in which, as Hart has argued, a judge has to exercise her discretion: ". . there are indeed areas of conduct where much must be left to be developed by courts or officials striking a balance, in the light of circumstances, between competing interests which vary in weight from case to case" (Hart 1994: 135). ${ }^{30}$

\section{6.- To conclude}

In this essay we have discussed the ways in which different approaches to meaning treat a variety of cases of interpretive disagreement. We have argued that NTR is not committed to

\footnotetext{
${ }^{26}$ The 'Madagascar' case was presented as a problem for NTR in (Evans 1973). Michael Devitt has often pointed out that instead of a problem, the 'Madagascar' case is a confirmation of NTR, for it shows that there was a new grounding of reference in an object that originated a new chain of communication.

${ }^{27}$ See (Epstein 2015) for an argument against the authority of a judge to establish meaning.

${ }^{28}$ Although we can imagine circumstances in which the issue may legitimately arise, if tomatoes were gradually modified to include synthetic elements.

${ }^{29}$ We think that our discussion here goes along lines that would be acceptable to Punkett and Sundell, although they do not discuss in detail some of the cases brought up here.

${ }^{30}$ Nevertheless, the vast majority of cases are not indeterminate and hence they "do not require . . . a fresh judgment from case to case". (Hart 1994: 135)
} 
the claim that the application of a term can depend only on underlying essence, and we have presented a treatment of interpretive disagreements compatible with NTR.

We have also argued that Hartian conventionalism is not committed to descriptivism and that an account of different kinds of disagreement can be provided from a conventionalist perspective within the framework of NTR. Hence, the dispute between Dworkinians and Hartians does not depend on Hart's commitment to one or another semantic theory.

In our view, both in and out of the legal context a host of different considerations have an impact as regards which linguistic practice has to be considered relevant in the adjudication of disputes. Which of those considerations should be taken into account in different cases is the next important issue to address. As we see it, different theories of law have different conceptions of the nature of the relevant considerations, and the dispute between Dworkinians and Hartians can be seen from this perspective as a dispute over this issue. For a Hartian the considerations have a conventional character and for a Dworkinian they always depend ultimately on moral factors. We have not tried to fall on either side of the equation in this regard. But what our discussion shows, is that this particular dispute is not one whose resolution is within the domain semantics.

\section{References}

Almog, J., 1984: Semantic anthropology, in "Midwest studies in philosophy”, 9: 479-489.

Bix, B., 1993: Law, language and legal determinacy, Clarendon Press: Oxford.

Devitt, M., 1981: Designation, Columbia University Press: New York.

Devitt, M. and Sterelny, K., 1999: Language and Reality, Mass. MIT Press: Cambridge.

Donnellan, K., 1970: Proper names and identifying descriptions, in "Synthese", 21: 335-358.

Dupré, J., 1981: Natural Kinds and Biological Taxa, in "The Philosophical Review", 90: 6690.

Dworkin, R., 1986: Law's Empire, Hart Publishing: Oxford.

Dworkin, R., 2006: Justice in Robes, Harvard University Press: Cambridge.

Epstein, B., 2015: What Alabama's Roy Moore Got Right, in "The New York Times" February 16. Available at http://opinionator.blogs.nytimes.com/2015/02/16/what-alabamasroy-moore-gets-right/

Evans, G., 1973: The Causal Theory of Names, in "Proceedings of the Aristotelian Society", 47:187-208.

Frege, G., 1892: Über Sinn und Bedeutung, in "Zeitschrift für Philosophie und philosophische Kritik", 100: 25-50. Translated as On Sense and Reference by M. Black in "Translations from the Philosophical Writings of Gottlob Frege", P. Geach and M. Black (eds. and trans.), 2nd. ed., Blackwell: Oxford, 1960. 
Hart, H.,1994: The Concept of Law, 2nd ed., Oxford University Press: New York.

Jackman, H., 1999: We live forwards but understand backwards: Linguistic Practices and Future Behavior, in "Pacific Philosophical Quarterly", 80: 157-177.

Kripke, S., 1980: Naming and necessity, Harvard University Press: Cambridge.

Lewis, D., 1969: Convention. A Philosophical Study, Basil Blackwell: Oxford.

Ludlow, P., 2008: Cheap Contextualism, in "Philosophical Issues", 18: 104-129.

Marcus, R.B., 1993: Possibilia and Possible Worlds. Reprinted in Modalities, Oxford

University Press: New York. Originally published in "Grazer Philosophische Studien", 25-26 (1985/1986): 107-133.

Marmor, A., 2005: Interpretation and legal theory, 2nd. ed., Hart Publishing: Oregon.

Marmor, A., 2009: Social conventions. From language to law, Princeton monographs in philosophy: Oxford.

Mill, J.S., 1843: A System of Logic, Harrison and Co. Printers: London.

Moore, M., 1985: A Natural Law Theory of Interpretation, in "Southern California Law Review", 58: 277-398.

Moreso, J.J., 2010: Tomates, hongos y significado jurídico, in: J.J. Moreso et al, Los desacuerdos en el derecho, Fundación coloquio jurídico europeo: Madrid, 15-47.

Patterson, D., 1989a: Realist Semantics and Legal Theory, in "The Canadian Journal of law and jurisprudence", 2: 175-179.

Patterson, D., 1989b: What was Realism? A Reply to David Brink, in "The Canadian Journal of law and jurisprudence”, 2: 193-195.

Phillips, I., 2014: Cetacean Semantics, in “Analysis”, 74, 3: 379-382.

Plunkett, D. and Sundell, T., 2013a: Dworkin's Interpretivism and the Pragmatics of Legal Disputes, in "Legal Theory", 19: 242-281.

Plunkett, David and Sundell, T., 2013b: Disagreement and the Semantics of Normative and Evaluative Terms, in "Philosophers Imprint", 13: 1-37.

Plunkett, D. and Sundell, T., 2014: Antipositivist Arguments from Legal thought and Talk. The Metalinguistic Response, in: G. Hubb and D. Lind (eds.), Pragmatism, Law, and Language, Routledge: London, 56-75.

Putnam, H., 1975: The Meaning of "Meaning”, Philosophical Papers, Vol. II: Mind, Language, and Reality, Cambridge University Press: Cambridge.

Ramírez-Ludeña, L., 2015: Diferencias y deferencia, Marcial Pons: Madrid-Barcelona.

Russell, B., 1910-1911, Knowledge by Acquaintance and Knowledge by Description, in "Proceedings of the Aristotelian Society", XI, 108-128.

Sainsbury, M., 2014: Fishy Business, in "Analysis", 74, 1: 3-5.

Searle, J., 1958: Proper names, in “Mind”, 67: 166-73. 
Shapiro, S., 2007: The Hart-Dworkin Debate: A short guide for the perplexed, in: A. Ripstein, (ed.), Ronald Dworkin, Cambridge University Press: New York, 22-55.

Vilajosana, JM., 2010: El derecho en acción, Marcial Pons: Barcelona-Madrid. 